\title{
Societal Educational Debts Due to Racism and Sexism in Calculus-based Electricity and Magnetism Courses
}

\author{
Jayson M. Nissen \\ Nissen Education Research and Design, Corvallis, OR, 97330, USA \\ Ben Van Dusen \\ School of Education, Iowa State University, Ames, IA, 50011, USA
}

\begin{abstract}
The American Physical Society calls on its members to improve the diversity of physics by supporting an inclusive culture that encourages women and Black, Indigenous, and people of color to become physicists. Introductory physics courses provide opportunities for recruiting and retaining diverse students or enacting policies and cultural practices that disproportionately harm students from minoritized groups. Introductory calculus-based electricity and magnetism courses have received far less attention from researchers than introductory mechanics courses. To better understand the role introductory electricity and magnetism courses play in the lack of diversity in physics, we investigated the intersecting relationships between racism and sexism in inequities in student conceptual knowledge using a quantitative critical framework. The analyses used Bayesian hierarchical linear models to examine students' conceptual knowledge as measured by the Conceptual Survey of Electricity and Magnetism. The data came from the LASSO database and included 3,686 students from 83 calculus-based courses at 16 institutions. The model indicated society owed educational debts in conceptual knowledge due to racism, sexism, or both to Black, Hispanic, Asian, and White Hispanic students and White women. Of these groups, society owed the largest educational debts to Black students. The courses, of which almost all used collaborative instruction ( 81 of 83) supported by learning assistants (66 of 83), added to the educational debts owed to Black students, maintained the debts owed to Hispanic and White Hispanic students and White women, and mitigated the debts owed to Asian students.
\end{abstract}

2021 PERC Proceedings edited by Bennett, Frank, and Vieyra; Peer-reviewed, doi.org/10.1119/perc.2021.pr.Nissen

Published by the American Association of Physics Teachers under a Creative Commons Attribution 4.0 license. Further distribution must maintain the cover page and attribution to the article's authors. 


\section{INTRODUCTION}

The American Physical Society strives to improve the diversity of physics by supporting an inclusive culture that encourages women and Black, Indigenous, and people of color (BIPOC) [1] to become physicists [2]. Physicists pursue this goal, in part, by investigating the barriers physics education imposes on women and BIPOC students. This research includes gender differences in course grades [3-7], conceptual knowledge [8, 9], and affective characteristics such as selfefficacy [4, 10, 11] and attitudes [4, 6, 12-15]. Research has also investigated sexual harassment and discrimination in physics courses [16, 17]. Similar work has investigated these issues for BIPOC students in physics: course grades [7, 18, 19], conceptual knowledge [6, 9, 19-22], classroom experiences [23-30], and affective characteristics [26, 31]. In this study, we investigated the extent to which introductory calculus-based electricity and magnetism courses mitigate, perpetuate, or exacerbate the educational debts due to sexism, racism, or both that society owes minoritized students. See Section IV.B for more information on educational debts.

\section{RESEARCH QUESTION}

To investigate the intersecting roles that sexism and racism play in shaping physics student learning, we asked the following question: To what extent do second-semester calculusbased physics courses mitigate, perpetuate, or exacerbate the educational debts that society owes minoritized students?

\section{BACKGROUND}

Significant research has investigated the low representation of women in undergraduate physics, which has remained at approximately 20\% since 1997 [32]. Cheryan and colleagues' [11] found that masculine cultures, gender differences in self-efficacy, and a lack of early educational experiences aligned with the lower participation of women in physics, computer science, and engineering compared to biology, chemistry, and mathematics. Madsen et al. [8] review of 26 studies found consistent gender differences benefiting men for conceptual learning in introductory physics courses, but few studies looked at electricity and magnetism, the focus of this study. These results align with more recent work showing differences in conceptual learning favoring men [9]. Gender differences at the beginning of the term align with girls having fewer early educational opportunities in physics [11]. Seymour and Hewitt [33] found evidence of masculine cultures driving highly competent women out of STEM majors. Most women report experiencing sexual harassment during their physics education [16, 17]. Henderson et al. [10] found consistent gender differences in self-efficacy in physics, where self-efficacy tended to decrease, but not in chemistry, mathematics, or biology, where self-efficacy tended to increase.
Quantitative studies show racial differences in conceptual knowledge before instruction that courses either maintained Kost et al. [6], Watkins [20], Brewe et al. [21] or increased Van Dusen and Nissen [9], Van Dusen et al. [22]. Nissen et al. [31] found introductory physics courses maintained large inequalities in physics attitudes between White [34] students and Asian, Black, and Hispanic students.

Several qualitative studies have focused on the lived experiences of students of color [23], Black students [24, 26], Black women [25, 27-29], and women of color [30] in physics. The students experienced race as a salient component of their physics education. Peers and faculty members often ignored and avoided them, dissuaded them from pursuing STEM degrees, and excluded them from insider knowledge needed to succeed in their education [28, 30, 33, 3539]. These negative experiences occurred less frequently, however, for Black men at Historically Black Colleges and Universities (HBCUs) [39].

Intersectional studies show the combined burden of racism and sexism society places on women of color $[40,41]$. Black women face marginalization from White men, White women, and Black men [39]. Black women also experience recognition as physicists pushing them away from continuing to do physics more often than Black men [26]. Clancy et al. [42] found that women of color uniquely faced barriers in astronomy and planetary sciences that White women did not face.

\section{CONCEPTUAL FRAMEWORK}

\section{A. Quantitative Critical Race Theory (QuantCrit)}

We used a Quantitative Critical (QuantCrit) framework $[43,44]$ in this investigation. Below, we describe four principles of QuantCrit that guided this research.

1. The centrality of oppression - Educational inequities come from oppressive power structures that create educational and societal systems that cater to students from dominant groups. As such, we follow Ladson-Billings' [45, 46] framing of inequities in group performance as educational debts that society owes students due to their continual marginalization. We describe education debt in section IV.B. 2. Categories are neither 'natural' nor given - All data are socially constructed and reflect the hegemonic power structures that created them. Our models aggregated students by social identifiers for race and gender. While these categories are social constructs that maintain oppressive power structures, the socially-negotiated natures of race and gender do not diminish the effects of racism and sexism. We reflected this in our writing by naming racism and sexism as the causes of educational debts identified by the models. We strove to respect students' identities in how we collected and represented their self-identified races and genders in our models.

3. Data is not neutral and cannot 'speak for itself' - Racist and sexist assumptions can shape every stage of collecting, analyzing, and interpreting data [47, 48]. For example, in 
this work we do not present p-values because they depend on sample sizes and can lead researchers to dismiss meaningful inequities due to lack of representation in minoritized groups [49], which we detail in Sec. V.

4. The importance of intersectionality - Identity is multifaceted; each aspect dynamically intersects with each other and society's associated oppressive power structures to shape experience [50]. For example, Black women experience racism differently from Black men and sexism differently from White women. In this analysis, we accounted for the dynamic interactions between sexism and racism by including interaction terms for race and gender.

\section{B. Operationalizing Equity}

We operationalized $[43,51]$ equity to interpret our findings from an antiracist perspective. Kendi [52] defines antiracism as the ideas, beliefs, and policies that hold racial groups as equal. From this antiracist perspective, society's educational debts result from racial and gender discrimination. We operationalized equity as equality of outcomes to align with this definition. Equality of outcomes occurs when students from different gender, race, and ethnic groups have the same average achievement at the end of a course and are not owed educational debts on that metric [51, 53-55]. This perspective argues a just education system must allocate more resources and opportunities to the students owed educational debts to begin repaying them and eliminating inequities.

Figure 1 illustrates our conception of society's educational debts. Students enter a course with different skill or knowledge distributions due to oppression, e.g., systemic racism. Courses can then either mitigate, perpetuate, or exacerbate those educational debts. Figure 1 illustrates the most extreme forms of mitigation (the achievement of equality of outcomes and the full repayment of the educational debt) and exacerbation (the complete denial of education to the minoritized group). Society's educational debts are multifaceted and deeply rooted. The repayment of one educational debt does not imply paying all educational debts to a minoritized group.

\section{METHODS}

The data came from the Conceptual Survey of Electricity and Magnetism (CSEM) [56]. We accessed the data through the Learning About STEM Student Outcomes (LASSO) platform [57]. The LASSO platform collects large-scale, multiinstitution data by administering, scoring, and analyzing research-based assessments online. The LASSO platform makes an anonymized version of its database of student and course data available to support research. The database only includes students who consented to share their data with researchers. The data came from 3,686 students in 83 courses from 14 institutions. Of the 83 courses, 66 used the learning assistant model[58, 59] to implement collaborative instruc-

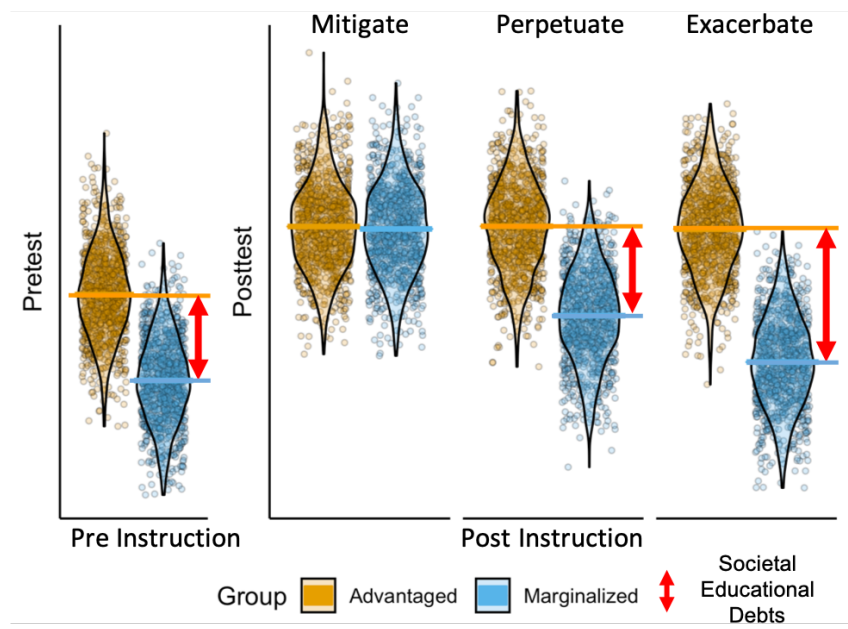

FIG. 1: Society's educational debts before and after instruction with three potential outcomes: mitigate, perpetuate, or exacerbate. These educational debts measures of average differences between overlapping groups, not absolute differences between individuals.

TABLE I: Descriptive statistics

\begin{tabular}{|c|c|c|c|c|c|c|c|c|}
\hline \multirow[b]{2}{*}{ Race } & \multirow[b]{2}{*}{ Gender } & Total & \multicolumn{3}{|c|}{ Pretest } & \multicolumn{3}{|c|}{ Post-test } \\
\hline & & $\mathrm{N}$ & $\mathrm{N}$ & Mean & S.D. & $\mathrm{N}$ & Mean & S.D. \\
\hline \multirow{2}{*}{ Asian } & Men & 357 & 259 & 36.1 & 17.3 & 259 & 56.3 & 21.4 \\
\hline & Women & 293 & 202 & 33.0 & 17.3 & 221 & 53.0 & 21.1 \\
\hline \multirow{2}{*}{ Black } & Men & 90 & 67 & 29.5 & 15.9 & 57 & 42.7 & 20.2 \\
\hline & Women & 69 & 56 & 24.5 & 10.9 & 48 & 41.0 & 21.1 \\
\hline \multirow{2}{*}{ Hispanic } & Men & 100 & 87 & 27.3 & 10.0 & 67 & 48.1 & 24.1 \\
\hline & Women & 63 & 53 & 23.3 & 9.0 & 43 & 38.7 & 22.5 \\
\hline \multirow{2}{*}{ White } & Men & 1621 & 1331 & 31.7 & 14.3 & 1103 & 51.2 & 20.8 \\
\hline & Women & 631 & 533 & 27.9 & 13.1 & 458 & 47.6 & 20.7 \\
\hline White & Men & 140 & 112 & 30.9 & 14.3 & 102 & 49.8 & 21.5 \\
\hline Hispanic & Women & 59 & 43 & 24.8 & 14.0 & 45 & 47.9 & 24.6 \\
\hline
\end{tabular}

tion and 81 of the 83 instructors reported engaging students in some form of collaborative instruction.

To clean the data, we removed the pretest or posttest score if the student took less than 5 minutes on the assessment or answered less than $80 \%$ of the questions. We then removed courses with less than ten students and less than $40 \%$ participation. Table I shows the descriptive statistics for the filtered data. After cleaning the data, we used hierarchical multiple imputation (HMI) with the hmi [60] and mice [61] packages in R-Studio V. 1.4.116 to address missing data. HMI maximizes statistical power while accounting for the hierarchical structure of the data [62-66].

To investigate society's educational debts, we developed a 3-level Bayesian hierarchical linear model (HLM) with tests nested within students nested within courses. HLM ac- 
counted for the nested nature of the data [67]. Bayesian models allowed using priors to inform the model. In Bayesian analysis, priors represent beliefs about the data (central tendencies and uncertainties) before analyzing the data. We used an identical analysis of data from the Force Concept Inventory collected with the LASSO Platform from 6,593 students in 168 courses at 16 institutions for priors. We developed the models using the rstan [68] and brms [69] packages.

To build a parsimonious model [70], we used the dredge package [71] to check if removing variables or interactions led to an Akaike information criterion corrected (AICc) at least two lower than our a priori model [72]. Dredging indicated our a priori model, with all variables, had the best fit.

The data set included demographic data for gender and race. We only investigated scores for populations with at least 20 students [73]. This guideline excluded variables for transgender, Hawaiian or Pacific Islander, or Native American or Alaskan Native in our models. To accurately represent course-level results, we combined these students and the students who did not reply to the demographics data into two categories: gender other and race other.

The model's variables included retake (students retaking the course), woman, gender other, Black, Asian, Hispanic, White, and race other. We included interactions between variables whenever the intersectional group had more than 20 students but not for race other and gender other. The model included interaction terms between Hispanic and White and between gender and each of the racial groups.

Motivated by the QuantCrit framework and recommendations in the statistics literature [74-76], we do not rely on or present $\mathrm{p}$-values for interpreting the models. P-values depend on sample size and can lead to selective reporting and attention perpetuating oppression against minoritized groups. Instead of using $p$ values, we used the overlap in the standard errors of the point estimates to inform our confidence in the size of society's educational debts. An overlap between one standard error bars approximately produces a p-value of 0.05 for a one-sided t-test. We did not, however, use overlap as a binary indicator of significance. We also used the consistency of results across similar comparisons (e.g., racism, sexism, or their intersection) to interpret model uncertainty.

\section{FINDINGS}

The model of conceptual knowledge for electricity and magnetism indicated clear educational debts owed by society due to racism, sexism, and their intersection, as shown in Table II and Fig. 2. Before and after instruction, the model indicated a clear educational debt due to sexism with lower estimated scores for women than men of the same race. The overlaps in the error bars for Black women and men and for White Hispanic women and men do indicate that the educational debts due to sexism may have slightly decreased for these two groups. However, the consistent educational debt due to sexism across all five racial groups and ten compar-

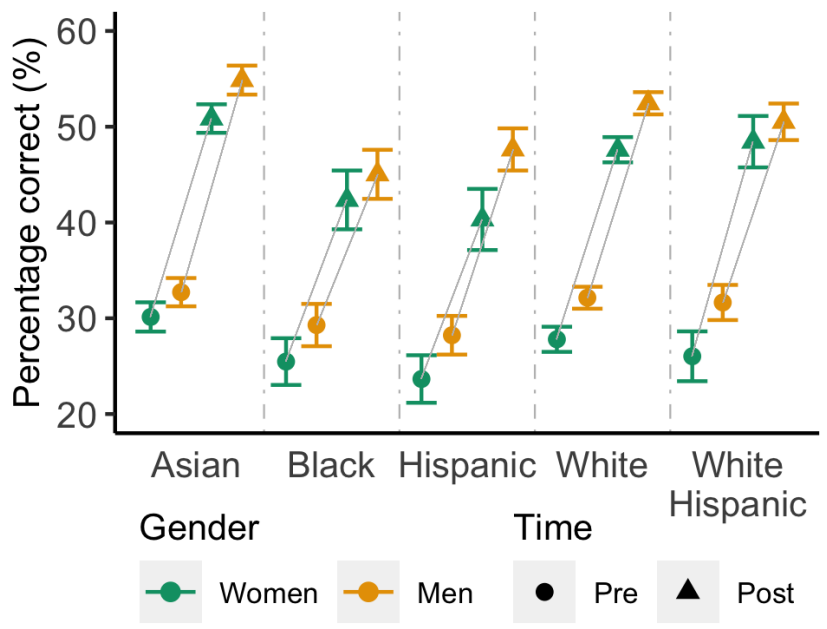

FIG. 2: Estimated CSEM scores with standard errors.

isons does not support interpreting this overlap as a repayment of these educational debts. The model also indicated society owed educational debts due to racism before and after instruction to Black and Hispanic students. The model did not provide consistent evidence of these societal educational debts due to racism owed to Asian and White Hispanic students. Asian women and men had similar scores to White women and men before instruction and higher scores after instruction, indicating that society does not owe Asian students overall an educational debt in this conceptual knowledge. White Hispanic and White women had similar scores both before and after instruction, while the differences were small between White Hispanic and White men before instruction and even smaller after instruction. The model shows the intersectionality of racism and sexism, with the largest educational debts being owed to Black and Hispanic women. While the difference between Black women and men was smaller after instruction this occurred in part because Black men had the smallest gain in their scores.

Smaller pretest standard deviations, see Table I, indicated a floor effect on the pretest. These floor effects caused smaller differences on the pretest and obscured the extent to which instruction mitigated, maintained, or exacerbated educational debts in conceptual knowledge. Therefore, we looked at the educational debts before and after instruction and the absolute gains for each group. These three pieces of information indicated that these electricity and magnetism courses exacerbated the educational debts society owed to Black women and men as the gains for these students (17.9 and 15.9) were lower than the gains for White men (19.5). The courses largely maintained the educational debts owed to Hispanic women (19.0), Hispanic men (19.5), White Hispanic men (19.9) and to a lesser extent White Hispanic women (20.6). The larger gains for Asian women (22.9) and men (21.5) than for White men indicated the courses mitigated and even fully repaid these societal educational debts. 
TABLE II: Estimated (est.) scores and standard errors (s.e.) based on the models.

\begin{tabular}{llllll}
\hline \hline & & \multicolumn{2}{c}{ Pre } & \multicolumn{2}{c}{ Post } \\
Race & Gender & Est. & S.E. & Est. & S.E. \\
\hline Asian & Men & 33.3 & 1.0 & 54.8 & 1.1 \\
Asian & Women & 28.6 & 1.1 & 51.5 & 1.2 \\
Black & Men & 29.2 & 1.5 & 45.1 & 2.1 \\
Black & Women & 25.8 & 1.9 & 43.3 & 2.7 \\
Hispanic & Men & 28.0 & 1.3 & 47.5 & 1.7 \\
Hispanic & Women & 22.7 & 1.8 & 41.7 & 2.7 \\
White & Men & 34.1 & 0.9 & 53.6 & 1.0 \\
White & Women & 28.5 & 1.1 & 48.6 & 1.1 \\
White Hispanic & Men & 32.0 & 1.5 & 51.9 & 1.7 \\
White Hispanic & Women & 28.5 & 2.2 & 49.0 & 2.5 \\
\hline \hline
\end{tabular}

\section{DISCUSSION AND CONCLUSIONS}

Society owing the largest pre-existing educational debts in conceptual knowledge to Black students, and Black women especially, and introductory electricity and magnetism courses adding to these educational debts aligns with systemic anti-Black racism in American society. Physics education researchers, including ourselves, need to dedicate energy not just to measuring this oppression but to fighting it. One step in repaying these educational debts is identifying instructional strategies at the course, department, institution, and societal level that repay these educational debts.

Almost every course in the study (81 of 83) used some form of collaborative instruction with 66 courses having used learning assistants to implement collaborative instruction. The exacerbation of the educational debts society owed to Black women and men indicates that collaboration alone does not repay educational debts. This limitation of collaborative instruction may follow from students replicating the oppressive power structures in broader society within the small group activities. This limitation of collaborative instruction may follow from how students engage in small group activities. The literature, detailed in Section III, describes Black students and women of colors' mistreatment by their peers and women experiencing sexual harassment in physics. Further investigations are needed to understand how small groups support or harm student outcomes and to provide instructors tools for setting expectations around norms that support just, collaborative-learning environments.

The repayment of this educational debt for Asian students does not infer that introductory electricity and magnetism courses repay other important educational debts. For example, recent work [31] indicates that these physics courses maintain large educational debts in the attitudes that students need to succeed as physics majors. The common practice of combining Asian and White students in statistical analyses can obscure injustices Asian students face in physics [77]. Aggregation of groups hiding inequities also extends to the results for Asian students. While on the whole, Asian stu- dents had similar outcomes to White students, the aggregation across Asian ethnicities likely hid inequities. Anti-Asian racism and inequities vary across Asian ethnicities with more privileged groups also being the more populous groups, leading to their performance overshadowing the inequities of the less represented groups [77, 78].

Hispanic, White Hispanic, and White appear in our models from our efforts to respect students' self-reported identities. We are not aware of any other studies in college science education that make similar aggregations of students. Distinguishing between White Hispanic and non-White Hispanic students was consistent with $67 \%$ of Hispanic Americans considering their Hispanic identity as part of their racial identity [79]. The smaller educational debts society owes to White Hispanic students than to Hispanic students indicates that combining these two groups may obscure the oppression Hispanic students face. These results also point to the need to understand better the diverse experiences of Hispanic students in college physics instruction.

\section{LIMITATIONS}

The study not accounting for class or socioeconomic status and not accounting for the filtering effect of introductory mechanics courses in who gets to take these electricity and magnetism courses adds to the uncertainty of these findings. Racism, sexism, and class oppression impact a large number of Americans. By not accounting for class oppression, the models assume that students in the study face equal class oppression and inequity, which is unlikely. For example, the combination of the filtering effect of making it into a second semester college physics course and society's educational debts may lead to the Black, Hispanic, and Asian students and women in the sample coming from more advantaged socioeconomic backgrounds than the White men in the sample. These relative socioeconomic advantages could obscure the oppression of racism and sexism. If this is the case, then the educational debts reported here due to racism and sexism understate society's actual educational debts to students from these minoritized groups. Racism, sexism, and class oppression co-evolved to hide and obscure the overlapping oppression they cause. In our future work, we will include data for socioeconomic status to minimize the extent to which class oppression obscures the impacts of racism and sexism. We will also use the LASSO database to investigate the impact that student persistence across physics courses has on our models of educational debts.

\section{ACKNOWLEDGEMENTS}

Thanks to Eleanor Close, Bud Talbot, Mollee Shultz, Sarah Hug, and Alicen Morley for feedback and the NSF for project funding (DUE-1928596). 
[1] We use BIPOC instead of students of color to emphasize the historic and ongoing marginalization of Black and Indigenous peoples in the United States.

[2] American Physical Society, Diversity Statement (2018).

[3] V. Sawtelle, E. Brewe, and L. H. Kramer, Exploring the relationship between self-efficacy and retention in introductory physics, Journal of research in science teaching 49, 1096 (2012).

[4] J. M. Nissen and J. T. Shemwell, Gender, experience, and selfefficacy in introductory physics, Physical Review Physics Education Research 12, 020105 (2016).

[5] L. E. Kost-Smith, S. J. Pollock, and N. D. Finkelstein, Gender disparities in second-semester college physics: The incremental effects of a "smog of bias", Physical Review Special Topics-Physics Education Research 6, 020112 (2010).

[6] L. E. Kost, S. J. Pollock, and N. D. Finkelstein, Characterizing the gender gap in introductory physics, Physical Review Special Topics-Physics Education Research 5, 010101 (2009).

[7] B. Van Dusen and J. Nissen, Associations between learning assistants, passing introductory physics, and equity: A quantitative critical race theory investigation, Physical Review Physics Education Research 16, 010117 (2020).

[8] A. Madsen, S. B. McKagan, and E. C. Sayre, Gender gap on concept inventories in physics: What is consistent, what is inconsistent, and what factors influence the gap?, Physical Review Special Topics-Physics Education Research 9, 020121 (2013).

[9] B. Van Dusen and J. Nissen, Equity in college physics student learning: A critical quantitative intersectionality investigation, Journal of Research in Science Teaching 57, 33 (2020).

[10] R. Henderson, V. Sawtelle, and J. M. Nissen, Gender \& selfefficacy: A call to physics educators, The Physics Teacher 58, 345 (2020).

[11] S. Cheryan, S. A. Ziegler, A. K. Montoya, and L. Jiang, Why are some stem fields more gender balanced than others?, Psychological Bulletin 143, 1 (2017).

[12] W. K. Adams, K. K. Perkins, N. S. Podolefsky, M. Dubson, N. D. Finkelstein, and C. E. Wieman, New instrument for measuring student beliefs about physics and learning physics: The colorado learning attitudes about science survey, Physical Review Special Topics - Physics Education Research 2, 010101 (2006).

[13] M. Good, A. Maries, and C. Singh, Impact of traditional or evidence-based active-engagement instruction on introductory female and male students' attitudes and approaches to physics problem solving, Physical Review Physics Education Research 15, 020129 (2019).

[14] C. H. Crouch, P. Wisittanawat, M. Cai, and K. A. Renninger, Life science students' attitudes, interest, and performance in introductory physics for life sciences: An exploratory study, Physical Review Physics Education Research 14, 010111 (2018).

[15] A. Traxler and E. Brewe, Equity investigation of attitudinal shifts in introductory physics, Physical Review Special TopicsPhysics Education Research 11, 020132 (2015).

[16] L. M. Aycock, Z. Hazari, E. Brewe, K. B. Clancy, T. Hodapp, and R. M. Goertzen, Sexual harassment reported by undergraduate female physicists, Physical Review Physics Education Research 15, 010121 (2019).
[17] R. S. Barthelemy, M. McCormick, and C. Henderson, Gender discrimination in physics and astronomy: Graduate student experiences of sexism and gender microaggressions, Physical Review Physics Education Research 12, 020119 (2016).

[18] A. B. Simmons and A. F. Heckler, Grades, grade component weighting, and demographic disparities in introductory physics, Physical Review Physics Education Research 16, 020125 (2020).

[19] J. Stewart, G. L. Cochran, R. Henderson, C. Zabriskie, S. DeVore, P. Miller, G. Stewart, and L. Michaluk, Mediational effect of prior preparation on performance differences of students underrepresented in physics, Physical Review Physics Education Research 17, 010107 (2021).

[20] J. E. Watkins, Examining issues of underrepresented minority students in introductory physics (Harvard University Cambridge, MA, 2010).

[21] E. Brewe, V. Sawtelle, L. H. Kramer, G. E. O'Brien, I. Rodriguez, and P. Pamelá, Toward equity through participation in modeling instruction in introductory university physics, Physical Review Special Topics-Physics Education Research 6, 010106 (2010).

[22] B. Van Dusen, J.-S. S. White, and E. Roualdes, The impact of learning assistants on inequities in physics student outcomes, arXiv preprint arXiv:1607.07121 (2016).

[23] S. L. Fries-Britt, T. K. Younger, and W. D. Hall, Lessons from high-achieving students of color in physics, New Directions for Institutional Research 2010, 75 (2010).

[24] S. Fries-Britt, J. Johnson, and B. Burt, Black students in physics: The intersection of academic ability, race, gender, and class., in Living at the Intersections: Social Identities and Black Collegians (Information Age Publishing, 2013) pp. 2139.

[25] S. Hyater-Adams, C. Fracchiolla, N. Finkelstein, and K. Hinko, Critical look at physics identity: An operationalized framework for examining race and physics identity, Physical Review Physics Education Research 14, 010132 (2018).

[26] S. Hyater-Adams, C. Fracchiolla, T. Williams, N. Finkelstein, and K. Hinko, Deconstructing black physics identity: Linking individual and social constructs using the critical physics identity framework, Physical Review Physics Education Research 15, 020115 (2019).

[27] K. Rosa and F. M. Mensah, Educational pathways of black women physicists: Stories of experiencing and overcoming obstacles in life, Physical Review Physics Education Research 12, 020113 (2016).

[28] E. O. McGee and L. Bentley, The troubled success of black women in stem, Cognition and Instruction 35, 265 (2017).

[29] K. M. Holmes, The Perceived Undergraduate Classroom Experiences of African-American Women in Science, Technology, Engineering, and Mathematics (STEM), Ph.D. thesis (2013).

[30] M. Ong, Body projects of young women of color in physics: Intersections of gender, race, and science, Social problems 52, 593 (2005).

[31] J. M. Nissen, I. H. M. Horses, and B. Van Dusen, Investigating society's educational debts due to racism and sexism in student attitudes about physics using quantitative critical race theory, Physical Review Physics Education Research 17, 010116 (2021). 
[32] R. Ivie and A. Porter, Women in physics and astronomy, 2019 (2019).

[33] E. Seymour and N. M. Hewitt, Talking about leaving (Westview Press, Boulder, CO, 1997).

[34] In this publication, we capitalize all races, including White, emphasizing that there is no default race and that they are all social constructs with associated sets of cultural practices.

[35] E. Mcpherson, Oh you are smart: Young, gifted African American women in STEM, Journal of Women and Minorities in Science and Engineering 23, 1 (2017).

[36] R. N. Johnson-Ahorlu, Our biggest challenge is stereotypes: Understanding Stereotype Threat and the academic experiences of African American undergraduates, The Journal of Negro Education 84, 382 (2013).

[37] A. C. Johnson, Unintended consequences: How science professors discourage women of color, Science Education 91, 805 (2007).

[38] A. Johnson, M. Ong, L. T. Ko, J. Smith, and A. Hodari, Common challenges faced by women of color in physics, and actions faculty can take to minimize those challenges, The Physics Teacher 55, 356 (2017).

[39] D. Dortch and C. Patel, Black Undergraduate Women and Their Sense of Belonging in STEM at Predominantly White Institutions, NASPA Journal About Women in Higher Education 10, 202 (2017).

[40] P. H. Collins and S. Bilge, Intersectionality (John Wiley \& Sons, 2016).

[41] K. Crenshaw, Mapping the margins: Intersectionality, identity politics, and violence against women of color, Stan. L. Rev. 43, 1241 (1990).

[42] K. B. Clancy, K. M. Lee, E. M. Rodgers, and C. Richey, Double jeopardy in astronomy and planetary science: Women of color face greater risks of gendered and racial harassment, Journal of Geophysical Research: Planets 122, 1610 (2017).

[43] F. K. Stage, Answering critical questions using quantitative data, New Directions for Institutional Research 2007, 5 (2007).

[44] D. Gillborn, P. Warmington, and S. Demack, Quantcrit: education, policy, 'big data' and principles for a critical race theory of statistics, Race Ethnicity and Education 21, 158 (2018).

[45] G. Ladson-Billings, From the achievement gap to the education debt: Understanding achievement in us schools, Educational researcher 35, 3 (2006).

[46] G. Ladson-Billings, Pushing past the achievement gap: An essay on the language of deficit, The Journal of Negro Education , 316 (2007).

[47] A. Covarrubias, P. E. Nava, A. Lara, R. Burciaga, V. N. Vélez, and D. G. Solorzano, Critical race quantitative intersections: A testimonio analysis, Race Ethnicity and Education 21, 253 (2018).

[48] T. Zuberi, E. Bonilla-Silva, et al., White logic, white methods: Racism and methodology (Rowman \& Littlefield Publishers, 2008).

[49] V. Amrhein, D. Trafimow, and S. Greenland, Inferential statistics as descriptive statistics: There is no replication crisis if we don't expect replication, The American Statistician 73, 262 (2019).

[50] K. Crenshaw, Mapping the margins: Intersectionality, identity politics, and violence against women of color, Standard Legal Review 43, 1241 (1990).

[51] I. Rodriguez, E. Brewe, V. Sawtelle, and L. H. Kramer, Impact of equity models and statistical measures on interpretations of educational reform, Physical Review Special Topics-Physics Education Research 8, 020103 (2012).

[52] I. X. Kendi, Stamped from the beginning: The definitive history of racist ideas in America (Random House, 2017).

[53] W. G. Secada, Equity in education (Falmer Press, 1989).

[54] O. Espinoza, Solving the equity-equality conceptual dilemma: a new model for analysis of the educational process, Educational Research 49, 343 (2007).

[55] O. Lee, Equity implications based on the conceptions of science achievement in major reform documents, Review of Educational Research 69, 83 (1999).

[56] D. P. Maloney, T. L. O'Kuma, C. J. Hieggelke, and A. Van Heuvelen, Surveying students' conceptual knowledge of electricity and magnetism, American Journal of Physics 69, S12 (2001).

[57] B. Van Dusen, Lasso: A new tool to support instructors and researchers, American Physics Society Forum on Education Fall 2018 Newsletter (2018).

[58] K. E. Gray, D. C. Webb, and V. K. Otero, Effects of the learning assistant model on teacher practice, Physical Review Physics Education Research 12, 020126 (2016).

[59] A. P. Barrasso and K. E. Spilios, A scoping review of literature assessing the impact of the learning assistant model, International Journal of STEM Education 8, 1 (2021).

[60] M. Speidel, J. Drechsler, and S. Jolani, hmi: Hierarchical Multiple Imputation (2018), r package version 0.9.13.

[61] S. van Buuren and K. Groothuis-Oudshoorn, mice: Multivariate Imputation by Chained Equations in R, Journal of Statistical Software 45, 1 (2011).

[62] P. D. Allison, Missing data, Vol. 136 (Sage publications, 2001).

[63] E. R. Buhi, P. Goodson, and T. B. Neilands, Out of sight, not out of mind: strategies for handling missing data, American Journal of Health Behavior 32, 83 (2008).

[64] J. L. Schafer, Multiple imputation: a primer, Statistical Methods in Medical Research 8, 3 (1999).

[65] C. A. Manly and R. S. Wells, Reporting the use of multiple imputation for missing data in higher education research, Research in Higher Education 56, 397 (2015).

[66] J. M. Nissen, R. Donatello, and B. Van Dusen, Missing data and bias in physics education research: A case for using multiple imputation, Physical Review Physics Education Research (2019).

[67] B. Van Dusen and J. M. Nissen, Modernizing use of regression models in physics education research: a review of hierarchical linear modeling, Physical Review Physics Education Research (2019).

[68] Stan Development Team, RStan: the R interface to Stan (2020), $r$ package version 2.19.3.

[69] P.-C. Bürkner, Advanced Bayesian multilevel modeling with the R package brms, The R Journal 10, 395 (2018).

[70] J. B. Johnson and K. S. Omland, Model selection in ecology and evolution, Trends in ecology \& evolution 19, 101 (2004).

[71] K. Bartoń, MuMIn: Multi-Model Inference (2019), r package version 1.43.6.

[72] K. P. Burnham and D. R. Anderson, A practical informationtheoretic approach, Model selection and multimodel inference, 2nd ed. Springer, New York (2002).

[73] J. P. Simmons, L. D. Nelson, and U. Simonsohn, False-positive psychology: Undisclosed flexibility in data collection and analysis allows presenting anything as significant, Psychological science 22, 1359 (2011). 
[74] R. L. Wasserstein and N. A. Lazar, The ASA's statement on p-values: context, process, and purpose, The American Statistician 70, 129 (2016).

[75] R. L. Wasserstein, A. L. Schirm, and N. A. Lazar, Moving to a world beyond " $p<0.05$ ", The American Statistician 73, 1 (2019).

[76] V. Amrhein, D. Trafimow, and S. Greenland, Inferential statistics as descriptive statistics: There is no replication crisis if we don't expect replication, The American Statistician (2018).

[77] D. Shafer, M. S. Mahmood, and T. Stelzer, Impact of broad categorization on statistical results: How underrepresented mi- nority designation can mask the struggles of both asian american and african american students, Physical Review Physics Education Research 17, 010113 (2021).

[78] S. T. Jang, The implications of intersectionality on southeast Asian female students' educational outcomes in the United States: A critical quantitative intersectionality analysis, American Educational Research Journal 55, 1268 (2018).

[79] K. Parker, R. Morin, J. M. Horowitz, M. H. Lopez, and M. Rohal, Multiracial in America: Proud, diverse, and growing in numbers, Washington, DC: Pew Research Center, 98 (2015). 